This work is licensed under a Creative Commons Attribution 3.0 License.

\title{
EDITORIAL
}

\section{Launch of the European Journal of Taxonomy (EJT)}

\author{
"The publication of results and the accessibility of publications \\ are a precondition for the efficiency of the research process." \\ (Sietmann 2008). \\ The EDIT / EJT Task Force
Laurence BÉNICHOU ${ }^{1}$, Koen MARTENS², Graham HIGLEY ${ }^{3}$, Isabelle GÉRARD ${ }^{4}$, Steven DESSEIN ${ }^{5} \&$ Daphné DUIN ${ }^{6}$ \\ ${ }^{1}$ Muséum national d'Histoire naturelle, Paris, France / Managing editor EJT \\ ${ }^{2}$ Royal Belgian Institute of natural Sciences, Brussels, Belgium / Editor in Chief EJT \\ ${ }^{3}$ Natural History Museum, London, UK \\ ${ }^{4}$ Royal Museum for Central Africa, Tervuren, Belgium \\ ${ }^{5}$ National Botanic Garden of Belgium, Meise, Belgium \\ ${ }^{6}$ EDIT office, Paris, France
}

We are very pleased and proud to announce the launch of the European Journal of Taxonomy. The EJT is an international, online, fast-track, peer-reviewed, open access journal in descriptive taxonomy, covering subjects in zoology, entomology, botany, and palaeontology, owned and run by a Consortium of European Natural History Institutes.

EJT is a collaborative project outcome of the EDIT network.

The foundation of this new journal will inevitably raise some questions, not the least of which is why does a scientific field such as taxonomy need a new journal? Surely there are enough taxonomic journals already, some of them well-known and many well-established!

A core mission of Natural History Institutions (NHIs) is to contribute to the understanding of the natural world and our place in it, and to disseminate this knowledge. Correspondingly, many NHIs have been publishers of journals and monographic series since their foundation, for some over 200 years ago. A key aspect of NHI-publications is the description of species (and higher taxa) and the unravelling of their relationships to other species, i.e. taxonomy and classification. Biodiversity description and the formal naming of species is scattered across hundreds of journals, many of which are inaccessible and with small print runs. Today, several of these publications are at risk of extinction. Yet, dissemination of original research on biodiversity is crucial to the mission of NHIs.

In today's digital era, the field of scholarly publishing is rapidly changing and the journals of NHIs are faced with complex strategic and technical issues concerning visibility, access, format, and financial structure of their titles. The real challenge for institutional journals is to keep up with the rapid 
developments in online services and standards. Those journals that miss the digital boat may become obscure, user unfriendly and may disappear in the near future. In parallel, ever more institutional journals have been outsourced to private publishers and, with the need to be ever mindful of the 'ISI impact factor', have shifted their editorial focus from descriptive taxonomy to phylogenetic and molecular analytical research. The result is that today there are fewer NHI-driven communication channels for alpha (descriptive) taxonomy, and those that still exist usually do not have a wide circulation.

To reverse this downward spiral, a consortium of NHIs has decided to launch a new, co-published journal of taxonomy that will play an important role in moving the field to open-access publishing and digital archiving, while enabling the institutions to take a greater control of the dissemination of scientific information. NHIs are both producers and consumers of taxonomic research and it is in their interest to continue production and to provide access to high quality work in this domain. A jointly published journal of taxonomy, funded by several institutions, sends a strong political message about the importance of descriptive taxonomic research within NHIs in Europe and elsewhere. Descriptive taxonomy is needed by a wide user base.

Traditionally, public funds are used to subsidise either reader-based subscriptions (libraries) or authorpaid fees for open-access. As scientific publications are the fruit of public-funded research, we strongly believe that scholarly publications should be made accessible to all, at no charge. This is why the European Journal of Taxonomy (EJT) is applying an alternative public open-access business model where neither readers, nor authors have to pay fees for subscriptions or publication.

EJT endorses the view, that ability to use and reuse data as freely as possible is the key to innovation and further advancement of science (i2010 Digital libraries initiative). Therefore, the most suitable economic model for $E J T$ is open access without a charge-processing fee. This economic model will take away potential barriers for researchers to publish their work.

Our objective is to enhance coordination between NHIs aimed at setting up a cross-institutional strategy at an international level in order to promote the adoption of common standards and ways of working, wherever possible.

An extensive, international team of scientific editors will guard the scientific quality of papers published in $E J T$, so that high level taxonomic papers of interest to a wide and international scientific audience will be published (see www.europeanjournaloftaxonomy.eu). EJT will accept major taxonomic contributions, taxonomic revisions, checklists of taxa on at least (sub) continental scale and opinion papers related to progress made in descriptive taxonomy. All submissions will be handled fully electronically through the Open Journal System, which we will use in line with our philosophy of open access publishing. Peer reviewing will be rigorous, and both scientific and technical standards of the journal will be high.

Skilled publishing staff in the institutions constitute the production team of EJT. They will build a strong cross-institutional team, able to implement ongoing technical advances in the field of scientific publishing. Coordinating institutional resources into a single journal contributes to excellence, prevents repetition, and increases efficiency in the dissemination of taxonomic data, while providing a secure, long-term publishing and archiving platform at minimal cost.

Although the title of the journal might hint of geographic restriction, the scope of EJT is global: authorship and region of study are not intended to be exclusively European. Authors are, however, encouraged to involve European natural history collections by consulting extant material, or by depositing (type-) material related to the published papers in the collection of a European NHI. 
EJT aims to offer all the modern interactive web-based facilities of high-level, high impact journals. It will provide links to all leading biodiversity-related databases in which new names of species and genera will automatically be included. EJT sets a high standard in taxonomic publishing.

We hope that the members of the scientific community will find this new journal valuable and useful and will welcome it, both as authors and as readers.

Founding members of the EJT consortium are:

- Muséum national d'Histoire naturelle (Paris, France)

- Natural History Museum (London, UK)

- Royal Belgian Institute of Natural Sciences (Brussels, Belgium)

- Royal Museum for Central Africa (Tervuren, Belgium)

- National Botanic Garden of Belgium (Meise, Belgium).

Other potential members are presently being considered. We plan to enlarge the consortium to at least 10-15 European members, more if possible. This will enable us to continue enlarging the publication platform for taxonomy. Because of its focus, EJT belongs to taxonomists, and we encourage taxonomists to engage with this initiative.

We thank all members of European Distributed Institute of Taxonomy (EDIT) who have shown an interest in the creation of this journal, and in particular Simon Tillier, the EDIT coordinator, for endowing this initiative both in principle and in practice. Our gratitude goes also to Patrick Grootaert, from RBINS (Brussels, Belgium) and Michèle Ballinger from CNRS (Paris, France) who have both actively supported the project from the start. We are also grateful for the enthusiasm and professionalism of the team of journal managers endlessly working to improve EJT: Natacha Beau, Kristiaan Hoedemakers and Charlotte Thionois. PKP (Public Knowledge Project) (http://pkp.sfu.ca/) kindly assisted us with the adaptation and implementation of their OJS (Open Journal System) system.

\section{References}

i20 10 Digital libraries initiative, December 2009. Final report: Digital libraries: recommendations and challenges for the future. High Level Expert Group on Digital Libraries: $17 \mathrm{p}$.

Sietmann R. 2008. Introduction: Quo vadis, Knowledge Society? In: OpenAccess-Opportunities and challenges $-A$ handbook by the European Commission and the German Commission for UNESCO.

Published on: 9 September 2011 